\title{
Changes in endopolygalacturonase levels and characterization of a putative endo- $P G$ gene during fruit softening in peach genotypes with nonmelting and melting flesh fruit phenotypes
}

\author{
S. Morgutti, N. Negrini, F. F. Nocito, A. Ghiani, D. Bassi and M. Cocucci \\ Dipartimento di Produzione Vegetale, University of Milan, via Celoria 2, 20133 Milan, Italy
}

Author for correspondence:

Silvia Morgutti

Tel: +390250316530

Fax: +390250316521

Email: silvia.morgutti@unimi.it

Received: 10 January 2006

Accepted: 24 March 2006

\section{Summary}

- The changes in endopolygalacturonase (endo-PG) levels and endo- $P G$ expression in nonmelting flesh (NMF) and melting flesh (MF) peach fruits (Prunus persica) during softening were studied. The endo- $P G$ gene was analysed to identify polymorphisms exploitable for early marker-assisted selection (MAS) of flesh texture.

- The role of endo-PG in softening was assessed by western and northern blotting and by biochemical analyses. Polymorphisms in the endo- $P G$ gene were revealed by reverse transcription-polymerase chain reaction (RT-PCR) and sequencing.

- An endo-PG protein was detected in both NMF and MF fruits. The levels of this endo-PG protein were higher and increased with softening in MF fruits, but remained lower and were constant in NMF fruits. The different levels of endo-PG appeared to be caused by the differential expression of an endo- $P G$ gene, whose open-reading frame (ORF) showed five single nucleotide polymorphisms (SNPs) in NMF 'Oro A' compared with MF 'Bolero'. One of these SNPs allowed us to determine the allelic configuration at the melting flesh $(M)$ locus and also seemed to be exploitable for early MAS in other NMF/MF phenotypes.

- The NMF phenotype does not seem to be caused by a large deletion of the endo- $P G$ gene.

Key words: cleaved amplified polymorphic sequence (CAPS), endopolygalacturonase (endo-PG) levels, endo-PG expression, marker-assisted selection (MAS), nonmelting flesh/melting flesh phenotype, Prunus persica, single nucleotide polymorphisms (SNPs).

New Phytologist (2006) 171: 315-328

(๑) The Authors (2006). Journal compilation @ New Phytologist (2006)

doi: $10.1111 / \mathrm{j} .1469-8137.2006 .01763 . x$

\section{Introduction}

Overall organoleptic quality of the peach (Prunus persica) fruit is mainly caused by the components of fruit taste (sugars, organic acids and volatiles) and flesh texture. The latter is one of the most important factors determining the consumer's perception of peach fruit quality (Bruhn, 1994). Peaches are classified as either melting flesh (MF) or nonmelting flesh (NMF) on the basis of fruit texture. Decrease in fruit firmness occurs during ripening of both phenotypes, but is more pronounced in MF fruits, where marked loss of firmness ('melting') occurs in the final stages of ripening (Brovelli et al., 1998). For this reason, if MF peaches are left to ripen on the tree to achieve maximum eating quality, they are very easily damaged during handling and shipping. Some current breeding programmes are developing NMF peaches for the fresh market which can fully ripen on the tree and still retain sufficient firmness to allow satisfactory handling and shelf-life.

Peach trees must be grown for at least 3 yr before they bear fruit, which makes breeding time-consuming, especially for 
fruit-specific characters. The dissection of fruit quality into a number of elementary components linked to genes of known function would be extremely useful for the early marker-assisted selection of fruit with desirable characteristics. Genes have been identified which control sucrose accumulation and fruit ripening in tomato (Yen et al., 1995; Klann et al., 1996) and carotenoid accumulation in red pepper (Huh et al., 2001). In peach, a few quantitative trait loci (QTLs) involved in fruit quality, such as size, titratable acidity, levels of malic and citric acids, levels of soluble sugars and soluble solids, have been identified (Abbott et al., 1998; Dirlewanger et al., 1998, 1999; Quarta et al., 2000). A candidate gene-QTL co-location, involving a cDNA encoding a tonoplast $\mathrm{H}^{+}$-pyrophosphatase which energizes solute accumulation into the vacuole and QTLs for sucrose and soluble solid content, has been described recently (Etienne et al., 2002).

Likewise, identification of a single (or a few) genetic traits unequivocally linked to the process of flesh softening would be of great benefit. A genetic marker for the MF trait is also especially desirable because the trait shows only when fruits are mature.

Flesh firmness can be considered as a quantitative trait, being affected by several biochemical and physiological factors, such as differences in the levels of apoplastic $\mathrm{Ca}^{2+}$, regulation of cell turgor in relation to plasma membrane functionality and levels of intracellular osmolytes, changes in cell wall architecture, etc. The identification and cloning of genes of known function (i.e. genes involved in cell wall loosening) would allow evaluation of the possible effects of their polymorphism/s on flesh firmness variability.

Cell wall changes associated with the softening process, including modifications of the structure and composition of the constituent polysaccharides, have been related to the expression of a number of hydrolases and transglycosylases (reviewed in Fischer \& Bennett, 1991). The activities of several hydrolytic enzymes, such as polygalacturonases (PGs), pectinmethylesterases, endo-1,4- $\beta$-glucanases, endo-1,4- $\beta$ mannanase, $\alpha$-arabinosidase and $\beta$-galactosidase (Hatfield \& Nevins, 1986; Bonghi et al., 1998; Brummell et al., 2004) have been shown to increase during fruit ripening. The role of PG in fruit ripening has been studied extensively (reviewed in Hadfield \& Bennett, 1998). In peach, Pressey \& Avants (1973) showed that endo-PG (EC 3.2.1.15) and exo-PG (EC 3.2.1.67) were present in ripe fruit and that endo-PG activity increased during ripening, particularly in MF peaches (Orr \& Brady, 1993). The expression of the endo- $P G$ gene was very abundant in ripe MF fruits, whereas in NMF peaches only a deleted mRNA was detectable (Lester et al., 1994). The NMF phenotype was ascribed to a partial or a complete deletion of the endo-PG gene (Lester et al., 1996; Callahan et al., 2004) and no PG protein was detected in the NMF peaches studied, whereas it was detected in MF phenotypes (Lester et al., 1996). In other species, a close relationship between endo-PG and flesh softening has also been recognized. In pepper, the soft flesh and deciduous fruit is a dominant trait controlled by the $S$ gene encoding PG (Rao \& Paran, 2003). In European pear, softening closely parallels endo-PG expression (Hiwasa et al., 2003).

In the present study we examined the changes during ripening and flesh softening in the expression of an endo-PG gene, accumulation of endo-PG protein and degrees of endo-PG activity in the flesh of two parents ('Oro A', with the NMF phenotype, and 'Bolero', with the MF phenotype) and of two of their offspring. An analysis of the structure of the endo-PG gene has also been conducted in these and other NMF/MF accessions in order to identify polymorphisms that are potentially exploitable for the early marker-assisted selection of flesh firmness.

\section{Materials and Methods}

\section{Plant material}

Peach (P. persica L. Batsch) accessions grown at the Experimental Orchard of the Arboriculture, Viticulture, Forestry and Landscape Department of the University of Bologna (Italy) were used. Fruits from different NMF and MF accessions were monitored on the tree during ripening. The NMF/MF phenotype was assessed by sensory evaluation at the eating-ripe stage. 'Oro A' (NMF) and 'Bolero' (MF) were assessed together with their offspring 'BO 96014125' (NMF) and 'BO 96014137' (MF). Other accessions considered were 'Andross', 'Jonia' and 'BO 82010054 ' for the NMF phenotype and 'Springcrest', 'Springbelle' and 'Maycrest' for the MF phenotype. For each accession, all fruits were harvested at the same time, when the very first fruits on the tree were physiologically ripe. All fruits could be considered to be in stages 3-4 (Westwood, 1978) and covered the range from immature (full size fruit, no softening) to ripe (at the climacteric peak, with a fruit firmness of $20-30 \mathrm{~N}$ ) and over-ripe $(<10 \mathrm{~N})$.

\section{Ripening parameters and tissue sampling}

Immediately after harvest, all of the fruits from each accession were divided into ripening classes, based on epicarp ground colour as a maturity index (Delwiche \& Baumgardner, 1985). Epicarp colour parameters were measured at two different locations in the equatorial zone or from low or no-blush areas by using a Minolta Chromameter CR-200 reflectance colorimeter (Minolta Co., Osaka, Japan) (Robertson et al., 1990). For a preliminary classification of the fruits, the Minolta 'a' value, which records the degree of green-to-red pigmentation, was taken as being representative of the degree of ripening.

Flesh firmness measurements were performed by a hand penetrometer (Effegi, Milan, Italy) with an 8-mm flat probe at two equidistant locations in the equatorial region of each fruit after epicarp removal. Data were expressed in Newtons.

The epicarp and stone were removed and mesocarp samples from single fruits of known firmness were snap-frozen in liquid 
$\mathrm{N}_{2}$ and stored at $-80^{\circ} \mathrm{C}$. All subsequent analyses were conducted on single fruits.

\section{Protein extraction from mesocarp cell walls}

Protein extraction from mesocarp cell walls was performed as described by Moore \& Bennett (1994), with minor modifications. Mesocarp tissue $(15 \mathrm{~g})$ was crushed to powder with liquid $\mathrm{N}_{2}$ and $10 \%(\mathrm{w} / \mathrm{w})$ polyvinylpolypyrrolidone (PVPP) in a mortar. Four volumes of ice-cold low-salt extraction buffer [10 mM Na-acetate, pH 5.5, $20 \mathrm{~mm} \beta$-mercaptoethanol ( $\beta$-ME), $2 \mathrm{~mm}$ phenylmethylsulfonylfluoride (PMSF)] were added. The thawed slurry was centrifuged at $10000 \mathrm{~g}$ for 20 min at $4^{\circ} \mathrm{C}$ and the pellet washed with the same ice-cold buffer [four volumes on the basis of fresh weight (FW)]. After centrifugation, the pellet was resuspended in one volume per gram FW of high-salt extraction buffer ( $40 \mathrm{mM} \mathrm{Na}$-acetate buffer, $\mathrm{pH}$ 5.5, $1.5 \mathrm{~m} \mathrm{NaCl}, 20 \mathrm{~mm} \beta-\mathrm{ME}, 2 \mathrm{~mm}$ PMSF) and stirred overnight at $4^{\circ} \mathrm{C}$. The slurries were then centrifuged $(10000 \mathrm{~g}$, $30 \mathrm{~min}, 4^{\circ} \mathrm{C}$ ) after which the supernatants (high-salt extracts) were filtered through Miracloth (Calbiochem, Milan, Italy) and through a $45 \mu \mathrm{m}$ polyvinylidene difluoride (PVDF) membrane and then spun in a microconcentrator (Centricon Plus-20; Millipore, Billerica, MA, USA), with a total of two volumes of the same buffer without $\mathrm{NaCl}$ added at intervals to reduce the salt concentration. The final average protein concentration recovered in the cell wall extracts was approx. $3 \mu \mathrm{g}$ of protein per $\mu$ l. Suspensions were used either as such for nondenaturing polyacrylamide gel electrophoresis (PAGE) and determination of PG activity or treated with Plus One 2-D Clean-Up Kit (GE Healthcare Europe GmbH, Milan, Italy) for protein sodium dodecyl sulfate (SDS)-PAGE and immunoblotting.

\section{Protein determination}

Protein content was determined by the Bradford method (Bradford, 1976) using bovine serum albumin as a standard (Micro-Bio-Rad Protein Assay; Bio-Rad Laboratories, Segrate, Italy).

\section{Nondenaturing PAGE and activity staining}

Nondenaturing PAGE was performed at $4^{\circ} \mathrm{C}$ in a MiniProtean ${ }^{\mathrm{TM}}$ apparatus (Bio-Rad Laboratories) and in 10\% polyacrylamide gels, as described by Moore \& Bennett (1994). After electrophoresis, gels for activity staining were equilibrated twice, for $15 \mathrm{~min}$, in $10 \mathrm{~mm} \mathrm{Na}$-acetate buffer containing $1 \mathrm{~mm} \mathrm{1,2-}$ di(2-aminoethoxy) ethane- $N, N, N^{\prime}, N^{\prime}$-tetra-acetic acid (EGTA), $\mathrm{pH} 4.0$ (PG assay buffer) at $30^{\circ} \mathrm{C}$, incubated for $4 \mathrm{~h}$ at $30^{\circ} \mathrm{C}$ in $0.2 \%(\mathrm{w} / \mathrm{v})$ polygalacturonic acid (washed with $80 \%$ ethanol before use), $\mathrm{pH} 4.0$, and finally transferred into the same assay buffer for an additional $20 \mathrm{~h}$. Gels were then briefly rinsed with water before staining for $10 \mathrm{~min}$ in $0.5 \%(\mathrm{w} / \mathrm{v})$ methylene blue and destaining with water.

\section{SDS-PAGE}

Salt-extracted proteins from mesocarp cell walls were denatured in SDS sample buffer (Laemmli, 1970) and then analysed by tricine-SDS-PAGE (10\% total acrylamide/bis-acrylamide concentration; Schägger \& von Jagow, 1987) in an SE 600 Ruby Standard Dual Cooled Vertical Unit (Amersham Biosciences); gels were silver stained according to Heukeshoven \& Dernick (1985). Molecular weight markers were from Sigma-Aldrich (Sigma-Aldrich s.r.l., Milan, Italy).

\section{Anti-endo-PG polyclonal antibodies}

Database query [accession no. (acc. no.) CAA54150] allowed us to identify a conserved region (residues 355-369: CREIKLEDVKLTYKN) in the complete sequence of an endo-PG of ripe peach fruits (Lester et al., 1994). This was used by the Primm Company (Milan, Italy) to synthesize the corresponding ${ }_{2} \mathrm{HN}-\mathrm{CREIKLEDVKLTYKN}-\mathrm{COOH}$ polypeptide, which was subsequently conjugated with the immunogenic peptide keyhole limpet haemocyanin $(\mathrm{KLH})$ and inoculated in rabbit to produce antibodies. Antiserum was collected after $48 \mathrm{~d}$ and tested for antibody titre.

\section{Immunoprecipitation}

Salt-extracted proteins from mesocarp cell walls were added with the anti-endo-PG rabbit antiserum (1:5 total protein ratio), incubated on ice with gentle agitation for $1 \mathrm{~h}$ and immunoprecipitated by the addition of protein A-Sepharose (SigmaAldrich), activated according to the manufacturer's instructions. After an additional $1 \mathrm{~h}$ on ice with gentle agitation, immune complexes were removed by centrifugation $\left(16000 \mathrm{~g}, 1 \mathrm{~min}\right.$ at $\left.4^{\circ} \mathrm{C}\right)$.

\section{Western blotting}

Proteins were electroblotted for immunodetection onto PVDF membrane in a Multiphor II Nova-Blot (GE Healthcare Europe) apparatus. Nondenaturing gels were preincubated in $10 \mathrm{mM}$ 3-(cyclohexylamino)-1-propanesulfonic acid (CAPS)- $\mathrm{NaOH}$ buffer, $\mathrm{pH} 11.0$, containing $10 \%(\mathrm{v} / \mathrm{v})$ methanol and $0.1 \%$ (w/v) SDS, three times, for 10 min each, before electroblotting. Protein transfer was carried out at $4{ }^{\circ} \mathrm{C}$ (nondenaturing gels) or at room temperature (SDS-PAGE) at $0.8 \mathrm{~mA} \mathrm{~cm}^{-2}$ in the same CAPS-NaOH buffer without SDS. After blocking [for $2 \mathrm{~h}$, in PBS-Tween (PBS-T; $80 \mathrm{~mm} \mathrm{Na}_{2} \mathrm{HPO}_{4}, 20 \mathrm{~mm} \mathrm{NaH}_{2} \mathrm{PO}_{4}$, $100 \mathrm{~mm} \mathrm{NaCl}, 0.1 \%(\mathrm{v} / \mathrm{v})$ Tween-20) containing 3\% (w/v) nonfat dry milk powder], membranes were incubated overnight at $4^{\circ} \mathrm{C}$ with the anti-endo-PG antiserum $(1: 3000$ dilution in PBS-T). Blots were washed in PBS-T, incubated with anti-rabbit horseradish peroxidase-conjugated secondary antibody and then treated with chemiluminescent reagents (GE Healthcare Europe ECL Western Blotting Detection Kit) before exposure to Hyperfilm ECL (GE Healthcare Europe). 


\section{In vitro assay of endo-PG activity}

Aliquots of the protein suspensions obtained by saline extraction of mesocarp cell walls followed by concentration (see the section on protein extraction from mesocarp cell walls) were used to determine in vitro endo-PG activity (Pressey \& Avants, 1973; Gross, 1982).

\section{RNA isolation and cloning of endo-PG cDNA}

Total RNA was extracted from frozen mesocarp tissue (10 g) according to Loulakakis et al. (1996). First-strand cDNA was synthesized from $1 \mu \mathrm{g}$ of total RNA using Superscript II Reverse Transcriptase (Invitrogen, San Giuliano, Italy) primed with oligo $(\mathrm{dT})_{12-18}$ according to the manufacturer's instructions. Endo- $P G$ sequences were amplified by the polymerase chain reaction (PCR; 2 min of initial denaturation at $95^{\circ} \mathrm{C}$, followed by 35 cycles of denaturation at $94^{\circ} \mathrm{C}$ for $1 \mathrm{~min}$, annealing at $58^{\circ} \mathrm{C}$ for $40 \mathrm{~s}$ and a 1 -min extension at $72^{\circ} \mathrm{C}$ ) using two primers from the PRF5 endo-P $G$ cDNA sequence (Lester et al., 1994, forward: 5'-ATGGCGAACCGTAGAAGCCTCT-3'; reverse: 5'-CTACAAACAACTTGTAGGCTGAAC- $\left.3^{\prime}\right)$. Reaction products were analysed in a $1.5 \%(\mathrm{w} / \mathrm{v})$ agarose gel. A single band (of approx. $1200 \mathrm{bp}$ ) was purified and cloned into a pCR®4-Blunt II-TOPO® vector (Invitrogen). Sequences were determined by the Primm Company.

\section{Northern analysis}

Twenty micrograms of total RNA from fruit mesocarp were denatured and fractionated on a $1 \%$ formamide/formaldehyde denaturing gel. Fractionated RNA was transferred onto Hybond$\mathrm{N}$ membrane (GE Healthcare Europe) by capillary transfer with $10 \times$ standard saline citrate (SSC; $1 \times: 0.15 \mathrm{~m} \mathrm{NaCl}, 15 \mathrm{~mm} \mathrm{Na}-$ citrate, $\mathrm{pH}$ 7.0). The RNA was fixed at $80^{\circ} \mathrm{C}$ for $2 \mathrm{~h}$. The membrane was hybridized with ${ }^{32} \mathrm{P}[\mathrm{dATP}]$-labelled $e n d o-P G$ probe (see the 'RNA isolation and cloning of endo- $P G$ cDNA' section) synthesized using the PRIME-A-GENE® labelling system (Promega, Milan, Italy) at $60^{\circ} \mathrm{C}$ overnight and then washed three times at room temperature $(20 \mathrm{~min}, 0.1 \times \mathrm{SSC}, 1 \%$ $(w / v)(S D S)$ followed by two additional washes at $65^{\circ} \mathrm{C}$. The blot was then exposed to X-ray film (X-OMAT AR; Kodak, Rochester, NY, USA) at $-80^{\circ} \mathrm{C}$, and the film developed according to the manufacturer's recommendations.

\section{Isolation of DNA and genotyping}

Total genomic DNA from young leaves (100-150 mg FW) was prepared according to Geuna et al. (2004). DNAs were used as template for amplification with two primers, designed after alignment of the endo-PG cDNA clone with the partial genomic sequence of the peach endo-PG AC1 clone (acc. no.: AY262754; forward: 5'-AGGCGTTGCTTGTGGACCTG3'; reverse: 5'-CTCGCTGCAAGGGTGCTTGGGAC-3') at the annealing temperature of $60^{\circ} \mathrm{C}$. Restriction endonuclease digestion was carried out on the amplification products using the restriction enzyme BsrSI (Promega). The restriction enzyme mix $(10 \mu \mathrm{l})$, containing $2 \mu \mathrm{l}$ of restriction enzyme buffer and $15 \mathrm{U}$ of enzyme, was added to each tube and incubated for $3 \mathrm{~h}$ at $65^{\circ} \mathrm{C}$. Fragments were then separated on 2\% (w/v) agarose gels, visualized by ethidium bromide staining and sequenced (Primm).

\section{Chemicals}

All chemicals, unless stated otherwise, were purchased from Sigma-Aldrich.

\section{Results}

\section{Peach fruit flesh firmness during ripening}

All fruits from each accession were collected on a single date and sorted into classes on the basis of epicarp colour. Within each genotype, increasing 'a' values (degree of green-to-red pigmentation, data not shown) were taken as representative of increased ripening. Fruit firmness decreased with ripening. In 'Oro A' and 'BO 96014125', softening was less than in 'Bolero' and 'BO 96014137'. For the two accessions ('Oro A', 'BO 96014125') that had been classified as NMF in the field, the firmness values of the softest fruits was $25 \pm 3 \mathrm{~N}$. In the accessions classified as MF ('Bolero', 'BO 96014137'), the firmness of the softest fruits was $10 \pm 2 \mathrm{~N}$.

\section{Levels of endo-PG polypeptide in fruit mesocarp}

In order to assess whether the polyclonal antibodies produced (see the Materials and Methods) recognized the corresponding functional endo-PG protein, proteins were salt-extracted from a cell wall-enriched fraction from the mesocarp of a 'Bolero' fruit (MF phenotype) at the lowest firmness $(12 \mathrm{~N})$, separated by nondenaturing electrophoresis and assayed for both immunoreaction and endo-PG activity in a duplicate gel. The position of the cross-reaction band after nondenaturing electrophoresis (Fig. 1a, lane 1) closely matched that of the corresponding band of activity staining (Fig. 1b, lane 3), indicating that the antibodies against the synthetic polypeptide recognized a protein of the fruit cell walls, and that this protein had endo-PG activity. Pre-immune serum did not detect the protein (data not shown). The result was confirmed by the disappearance of both immunoreaction and endo-PG activity following removal of the antigen (endo-PG) from the protein extracts by immunoprecipitation with protein A-Sepharose (Fig. 1a,b, lanes 2 and 4, respectively).

Proteins were then extracted from the cell wall-enriched fraction of the flesh of single fruits of decreasing firmness from each accession, separated by SDS-PAGE and western blotted using anti-endo-PG antibodies as the probe. Figure 1(c) shows that the anti-endo-PG antibodies reacted with a polypeptide 
New

Phytologist

(a)

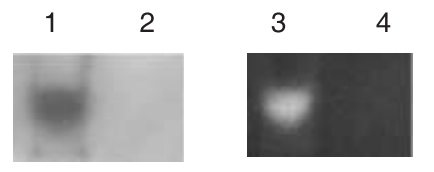

(c) (b)

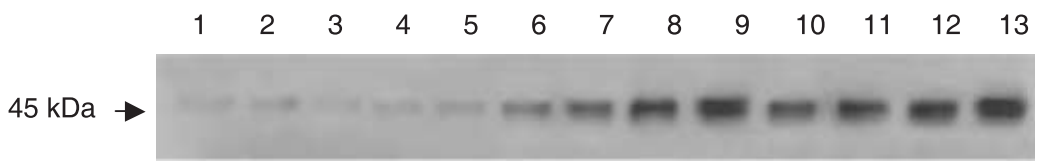

(d)

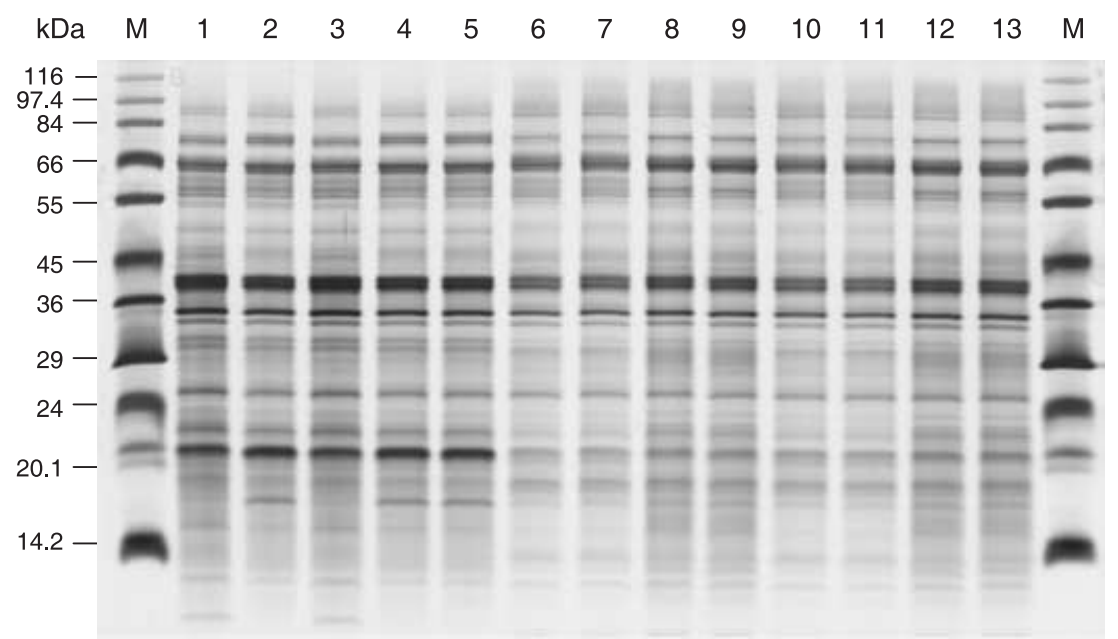

Fig. 1 Levels of endopolygalacturonase (endo-PG) in peach (Prunus persica) fruits with different nonmelting flesh (NMF)/melting flesh (MF) phenotypes. (a) Antibody validation. Western blot analysis was conducted after nondenaturing polyacrylamide gel electrophoresis (PAGE) of salt-extracted proteins from mesocarp cell walls of a soft $(12 \mathrm{~N}$ ) 'Bolero' fruit. The blot was reacted with the polyclonal antibodies raised against a conserved sequence of ripe peach endo-PG and visualized by chemiluminescence (see the Materials and Methods). (b) Activity staining was conducted in a duplicate gel of that shown in (a), as described in the Materials and Methods. Lanes 1 and 3, $20 \mu \mathrm{g}$ of protein; lanes 2 and 4, after immunoprecipitation of the same initial protein amount with protein A-Sepharose. The results of one experiment, representative of three, are shown. (c) Immunoblotting of endo-PG polypeptide after sodium dodecyl sulphate (SDS)-PAGE of proteins from the mesocarp cell walls of peach fruits with different NMF/MF phenotypes. Lane 1, 'Oro A' at $46 \mathrm{~N}$; lane 2, 'Oro A' at 34 N; lane 3, 'BO 96014125' at 49 N; lane 4, 'BO 96014125' at $32 \mathrm{~N}$; lane 5, 'BO 96014125' at $28 \mathrm{~N}$; lane 6, 'Bolero' at $54 \mathrm{~N}$; lane 7, 'Bolero' at $47 \mathrm{~N}$; lane 8, 'Bolero' at $28 \mathrm{~N}$; lane 9 , 'Bolero' at $12 \mathrm{~N}$; lane 10, 'BO 96014137' at $46 \mathrm{~N}$; lane 11, 'BO 96014137' at $39 \mathrm{~N}$; lane 12, 'BO 96014137' at $20 \mathrm{~N}$; and lane 13, 'BO 96014137' at 6.9 N. (d) Silver stain image of a duplicate gel of that electroblotted for (c). Lane M, molecular mass markers; lanes 1-13, as detailed for (c). Loading ( $20 \mu \mathrm{g}$ protein per lane) was equal in (c) and (d); the results of one experiment, representative of three, are shown.

band of approx. $45 \mathrm{kDa}$, a value consistent with the molecular mass values reported for catalytically active PG forms (Lee et al., 1990 and references therein; Brummell \& Harpster, 2001). The endo-PG polypeptide was present in both NMF and MF fruits, but at different levels compared with the equal protein loading of each lane (Fig. 1d). In all NMF fruits screened, the endo-PG polypeptide levels were very low and essentially independent of the value of flesh firmness (Fig. 1c, lanes 1-5), while in MF fruits the levels were higher, clearly detectable even in fruits with the firmest flesh, and increased markedly as flesh firmness decreased (Fig. 1c, lanes 6-13). Nevertheless, no quantitative correlation between the values of flesh firmness and the amounts of the polypeptide were demonstrated. Fruits with essentially the same value of flesh firmness $(c .46 \mathrm{~N})$ showed barely detectable accumulation of the endo-PG polypeptide in NMF 'Oro A' (Fig. 1c, lane 1) and much higher accumulation in MF 'Bolero' (Fig. 1c, lane 7) and 'BO 96014137' (Fig. 1c, lane 10). The same was true at $28 \mathrm{~N}$ flesh firmness for NMF 'BO 96014125' (Fig. 1c, lane 5) and MF 'Bolero' (Fig. 1c, lane 8). In addition, even within the same phenotypic group, no quantitative correlation was observed: in MF fruits, 'Bolero', at $47 \mathrm{~N}$ flesh firmness (Fig. 1c, lane 7), showed lower levels of the endo-PG polypeptide than 'BO 96014137' at $46 \mathrm{~N}$ (Fig. 1c, lane 10).

In vitro endo-PG activities of protein extracts from the cell walls of the same fruits, already tested for production of the 
endo-PG polypeptide, which showed maximum and minimum values of flesh firmness, ranged from an average value of $c .600$ pmol reducing groups released per $\mu \mathrm{g}$ of protein in $24 \mathrm{~h}$ in NMF 'Oro A' and 'BO 96014125', to $c .1200$ pmol reducing groups released per $\mu \mathrm{g}$ of protein in $24 \mathrm{~h}$ in MF 'Bolero' and 'BO 96014137', consistent with the higher levels of endoPG polypeptide of MF fruits (Fig. 1c) and confirming data previously reported in the literature (Pressey \& Avants, 1978; Orr \& Brady, 1993; Brummell et al., 2004).

\section{Isolation and sequencing of endo-PG cDNA clones}

In order to clarify the nature of the differences between NMF and MF fruit phenotypes with regard to the accumulation of the endo-PG polypeptide, regulation involving mRNA levels was investigated.

RNAs were extracted from the mesocarp of NMF 'Oro A' or MF 'Bolero' fruits at their maximum flesh softening ( $34 \mathrm{~N}$ and $12 \mathrm{~N}$, respectively); by reverse transcription (RT)-PCR with primers (see the Materials and Methods) designed on the peach PRF5 endo-PG cDNA (Lester et al., 1994), two cDNA fragments, one per each parental accession, were isolated (GenBank acc. no. DQ340810 for 'Oro A' and DQ340809 for 'Bolero', respectively). Molecular analysis (sequencing, alignment and comparison; Fig. 2) showed that both cDNA clones from 'Oro A' and 'Bolero' fruits were $1182 \mathrm{bp}$ long and corresponded to the complete PRF5 open reading frame (ORF) of the endo- $P G$ gene from the MF peach cultivar 'Flavorcrest' (Lester et al., 1994, GenBank acc. no. X76735). The ORF from MF 'Bolero' fruits presented seven single nucleotide polymorphisms (SNPs, at nucleotide positions 71, 76, 413, 533, 568, 569 and 1066) compared with the endo-PG sequence of MF 'Flavorcrest'. All of these SNPs induce a change in amino acid composition $\left(\mathrm{Ser}_{\mathrm{Fla}} 24\right.$ to $\mathrm{Thr}_{\mathrm{Bol}} 24, \mathrm{Leu}_{\mathrm{Fla}} 26$ to $\mathrm{Val}_{\mathrm{Bol}} 26$, $\mathrm{Cys}_{\mathrm{Fla}} 138$ to $\mathrm{Ser}_{\mathrm{Bol}} 138, \mathrm{Phe}_{\mathrm{Fla}} 178$ to $\mathrm{Cys}_{\mathrm{Bol}} 178, \operatorname{Arg}_{\mathrm{Fla}} 190$ to $\mathrm{Ala}_{\mathrm{Bol}} 190, \mathrm{Arg}_{\mathrm{Fla}} 356$ to $\mathrm{Ser}_{\mathrm{Bol}} 356$; Fig. 3). The ORF sequence from NMF 'Oro A' fruits, compared with that of MF 'Bolero', showed five SNPs at nucleotide positions 146, 516, 576, 579 and 806 (Fig. 2). Three (positions 516, 576, 579) did not induce any changes in the encoded amino acid, while the SNPs at positions 146 and 806 induced substitutions, respectively, of $\mathrm{Ser}_{\mathrm{Bol}} 49$ to $\mathrm{Phe}_{\mathrm{Oro}} 49$ and $\mathrm{Ser}_{\text {Bol }} 269$ to $\mathrm{Thr}_{\mathrm{Oro}} 269$. In particular, the $\operatorname{Thr}_{\mathrm{Oro}} 269$ residue can also be found in the polypeptidic sequence deduced from the endo-PG ORF of NMF fruits 'Feicheng' (NCBI acc. no. AF095577; Fig. 3).

The general comparison of the deduced amino acid sequences of the endo-PG protein of MF 'Bolero' and NMF 'Oro A' fruits with those of MF 'Flavorcrest' and NMF 'Feicheng' fruits confirms the presence of features widely shared among other eukaryotic PGs [i.e. four conserved domains, nine conserved Cys residues (55, 81, 135, 143, 221, 238, 318, 349, 355), a highly conserved His residue (position 242) in a Gly-rich region corresponding to domain III assigned to a catalytic function in all PGs sequenced, and a Tyr residue (position
311) strictly conserved and essential for activity (Hadfield \& Bennett, 1998; Hadfield et al., 1998; Redondo-Nevado et al., 2001)].

\section{Expression of an endo-PG gene in peach fruit mesocarp}

Our results show that an endo-PG polypeptide was present in the flesh of both NMF 'Oro A' and MF 'Bolero' fruits (Fig. 1c), suggesting that in both phenotypes an endo- $P G$ gene was expressed and translated, and produced at least one form of endo-PG recoverable (even if in lesser amounts in NMF than in MF fruits) in protein extracts obtained from the mesocarp cell walls. This hypothesis was strengthened by the data on the recovery of complete and only slightly different endo- $P G$ cDNA clones from ripe fruits from both 'Oro A' and 'Bolero' genotypes (Fig. 2).

RNAs produced in NMF 'Oro A' and MF 'Bolero' fruits with progressively decreasing values of flesh firmness $(46 \mathrm{~N}$ and $34 \mathrm{~N}$ for 'Oro A'; $54 \mathrm{~N}, 47 \mathrm{~N}, 28 \mathrm{~N}$ and $12 \mathrm{~N}$ for 'Bolero') were extracted and analysed by northern blotting, using the ${ }^{32} \mathrm{P}-$ labelled endo- $P G \mathrm{cDNA}$, obtained from ripe 'Bolero' fruits, as a probe. Figure 4 shows that the endo- $P G$ transcript was produced in both NMF 'Oro A' and MF 'Bolero' fruits. In 'Oro $A$ ', endo- $P G$ mRNAs were absent in the firmest fruits and were produced to a small extent only in the softest fruits (Fig. 4, lanes 5, 6), whereas in 'Bolero' their levels tended to be higher and markedly increased with flesh softening (Fig. 4, lanes 1-4).

These data are consistent with those concerning the endo-PG protein levels (as detected by western blots, Fig. 1c), indicating that in the NMF 'Oro A' genotype an endo- $P G$ gene is also present and is expressed with the production of an endo-PG protein.

\section{Molecular and CAPS analysis of an endo-PG fragment from genomic DNA}

Out of the five SNPs which characterized the endo-PG ORF in the NMF 'Oro A' accession, the one located at position $806\left(\mathrm{G}_{\mathrm{Bol}} \rightarrow \underline{\mathrm{C}}_{\text {Oro }}\right)$ generates a restriction site in the sequence ACTG GN recognized by the enzyme BsrSI. The same restriction region was also found 48 bp downstream (nucleotides 853-858) in the ORFs of both 'Oro A' and 'Bolero' (Fig. 2). The polymorphism at position 806 of the endo-PG ORF sequence allowed us to develop a molecular marker with the CAPS (Koniekzny \& Ausubel, 1993) procedure in order to obtain accession-specific digestion patterns of the peach endo-PG gene considered.

The endo-PG ORF sequences from 'Oro A' and 'Bolero' were aligned with the genomic sequence of the peach endo- $P G$ AC1 clone (acc. no. AY262754; Callahan et al. 2004), which represents the largest fragment of genomic sequence considered allelic to PRF5, available to date in GenBank. This allowed us to design primers useful for amplifying, in the genotypes of 


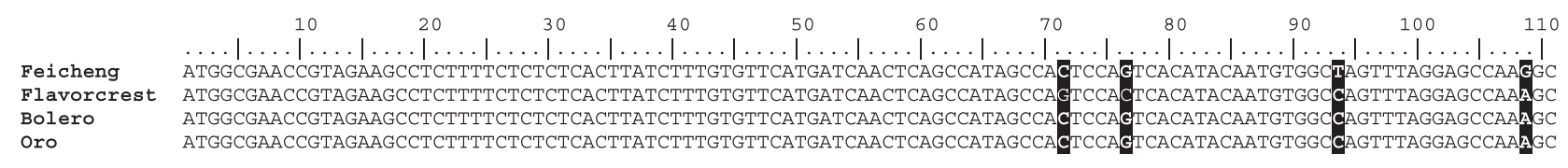

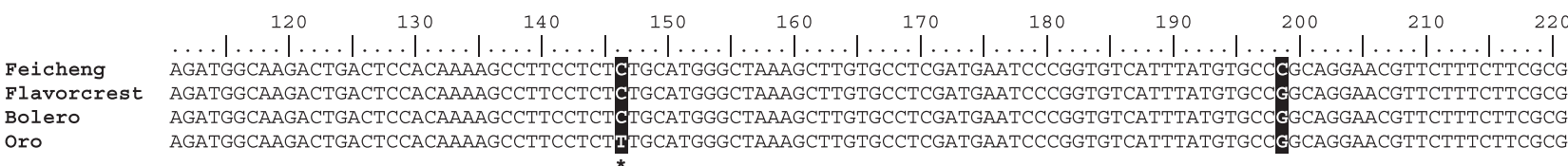
240
$\begin{array}{lllll}260 & 270 & 280 & 290 & 300\end{array}-310$
320
330

Feicheng Flavorcrest

Bolero ATGTGGTGTTMAGTGGCCTTGCAAGAACAATGCCATCACCTTCCGCATTGCCGGA_CCCTTGTGGCCCGTCGGATTACCGGGTCATCGGTAATGCAGCTAACTGGATT ATGTGGTGTTCAGTGGGCCTTGCAAGAACAATGCCATCACCTTCCGCATTGCCGGAACCCTTGTGGCCCCGTCGGATTACCGGGTCATCGGTAATGCAGCTAACTGGATT ATGTGGTTGTTCAGTGGGCCTTGCAAGAACAATGCCATCACCTTCCGCATTGCCGGAACCCTTGTGGCCCCGTCGGATTACCGGGTCATCGGTAATGCAGCTAACTGGATT ATGTGGTGTTCAGTGGGCCTTGCAAGAACAATGCCATCACCTTCCGCATTGCCGGAACCCTTGTGGCCCCGTCGGATTACCGGGTCATCGGTAATGCAGCTAACTGGATT

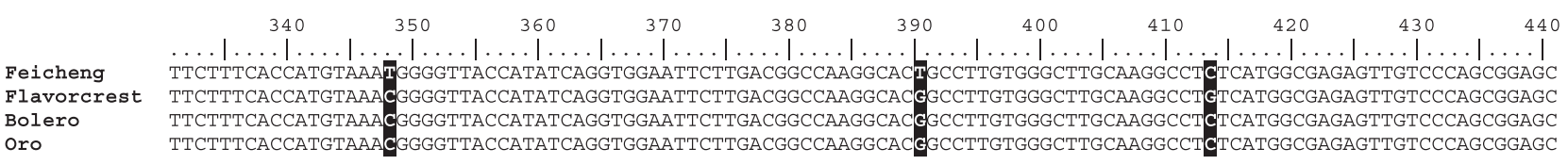

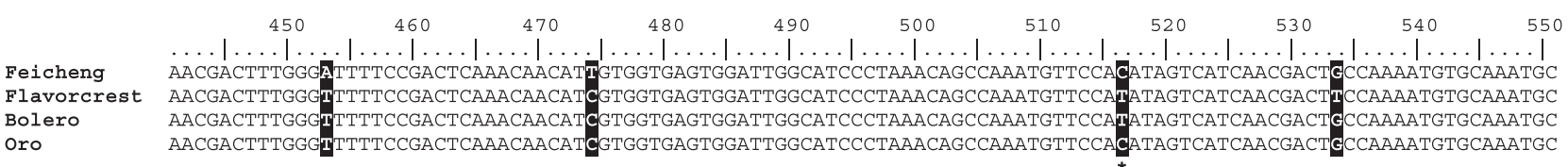
oro AACGACTTTGGGTTTTCCGACTCAAACAACATGGTGGTGAGTGGATTGGCATCCCTAAACAGCCAAATGTTCCACATAGTCATCAACGACTGCCAAAATGTGCAAATGC

Feicheng
Flavorcrest
Bolero

(2030 630

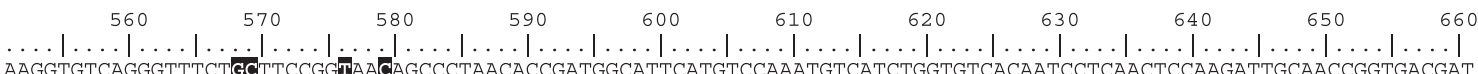
Bolero
Oro AAGGTGTCAGGGTTTCTECTTCCGGTAACAGCCCTAACACCGATGGCATTCATGTCCAAATGTCATCTGGTGTCACAATCCTCAACTCCAAGATTGCAACCGGTGACGAT AAGGTGTCAGGGTTTCTGCTTCCGGTAATAGCCCTAACACCGATGGCATTCATGTCCAAATGTCATCTGGTGTCACAATCCTCAACTCCAAGATTGCAACCGGTGACGAT AAGGTGTCAGGGTTTCTECTTCCGGEAACAGCCCTAACACCGATGGCATTCATGTCCAAATGTCATCTGGTGTCACAATCCTCAACTCCAAGATTGCAACCGGTGACGAT

Feicheng
Flavorcrest
Bolero
Oro

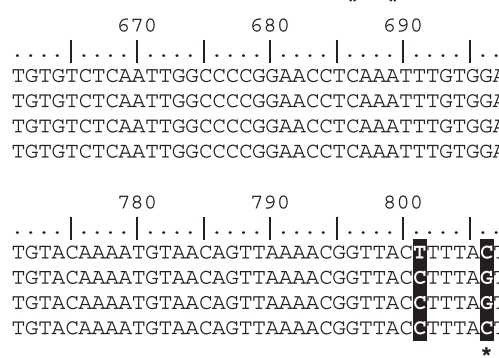

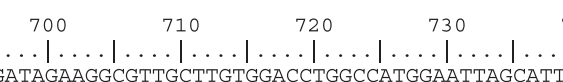
$740 \quad 750 \quad 760$

Bolero

Feicheng
Flavorcrest
Bolero
Oro

Feicheng
Flavorcrest
Bolero

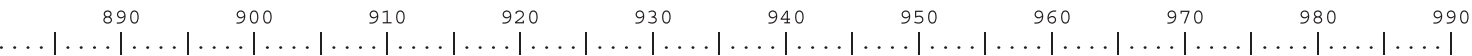

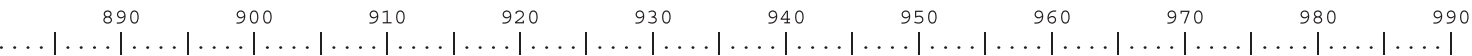

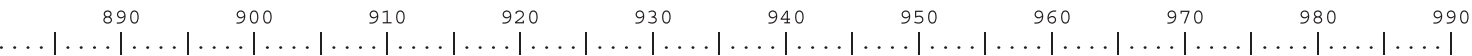

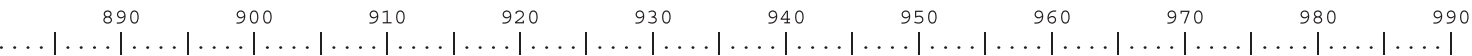

. $\ldots|\ldots| \ldots|\ldots| \ldots|\ldots|$ AACATGCTACAATGGTCAATGTCGAAAATCCTATTGTCATAGATCAACATTATTGCCCCGACAACAAAGGGTGCCCTGGTCAGGTTTCCGGAGTTCAAATTAGCGATGTG AACATGCTACAATGGTCAATGTCGAAAATCCTATTGTCATAGATCAACATTATTGCCCCGACAACAAAGGGTGCCCTGGTCAGGTTTCCGGAGTTCAAATTAGCGATGTG AACATGCTACAATGGTCAATGTCGAAAATCCTATTGTCATAGATCAACATTATTGCCCCGACAACAAAGGGTGCCCTGGTCAGGTTTCCGGAGTTCAAATTAGCGATGTG AACATGCTACAATGGTCAATGTCGAAAATCCTATTGTCATAGATCAACATTATTGCCCCGACAACAAAGGGTGCCCTGGTCAGGTTTCCGGAGTTCAAATTAGCGATGTG

Feicheng
Flavorcrest
Bolero
Oro

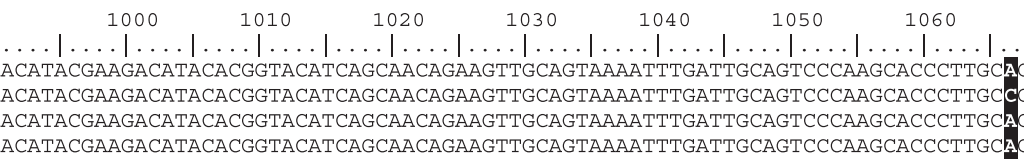
$|\ldots| \ldots|\ldots| \ldots|\ldots| \ldots|\ldots| \ldots \mid$ Oro

GCGATCAAATTGGAGGATGTGAAGCTTACTTA GCGAGATCAAATTGGAGGATGTGAAGCTTACTTA GCGAGATCAAATTGGAGGATGTGAAGCTTACTTA

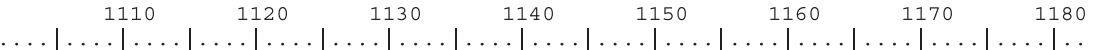

Feicheng Flavorcrest Bolero CAAGAACCAAGCAGCTGAGTCTTCATGTAGCCATGCAGATGGAACAACTGAGGGTGTGGTTCAGCCTACAAGTTGTTTGTAG CAAGAACCAAGCAGCTGAGTCTTCATGTAGCCATGCAGATGGAACAACTGAGGGTGTGGTTCAGCCTACAAGTTGTTTGTAG CAAGAACCAAGCAGCTGAGTCTTCATGTAGCCATGCAGATGGAACAACTGAGGGTGTGGTTCAGCCTACAAGTTGTTTGTAG CAAGAACCAAGCAGCTGAGTCTTCATGTAGCCATGCAGATGGAACAACTGAGGGTGTGGTTCAGCCTACAAGTTGTTTGTAG

Fig. 2 Comparison of the nucleotide sequences of the peach (Prunus persica) endopolygalacturonase (endo- $P G$ ) open-reading frames (ORFs) from nonmelting flesh (NMF) 'Feicheng' (accession no. AF095577), melting flesh (MF) 'Flavorcrest' (accession no. X76735), MF 'Bolero' and NMF 'Oro A' fruits. The 'Bolero' and 'Oro A' sequences were obtained from the endo- $P G$ cDNA clones from ripe fruits. The reverse contrast marks the presence of single nucleotide polymorphisms (SNPs); asterisks mark SNPs between 'Bolero' and 'Oro A'. 


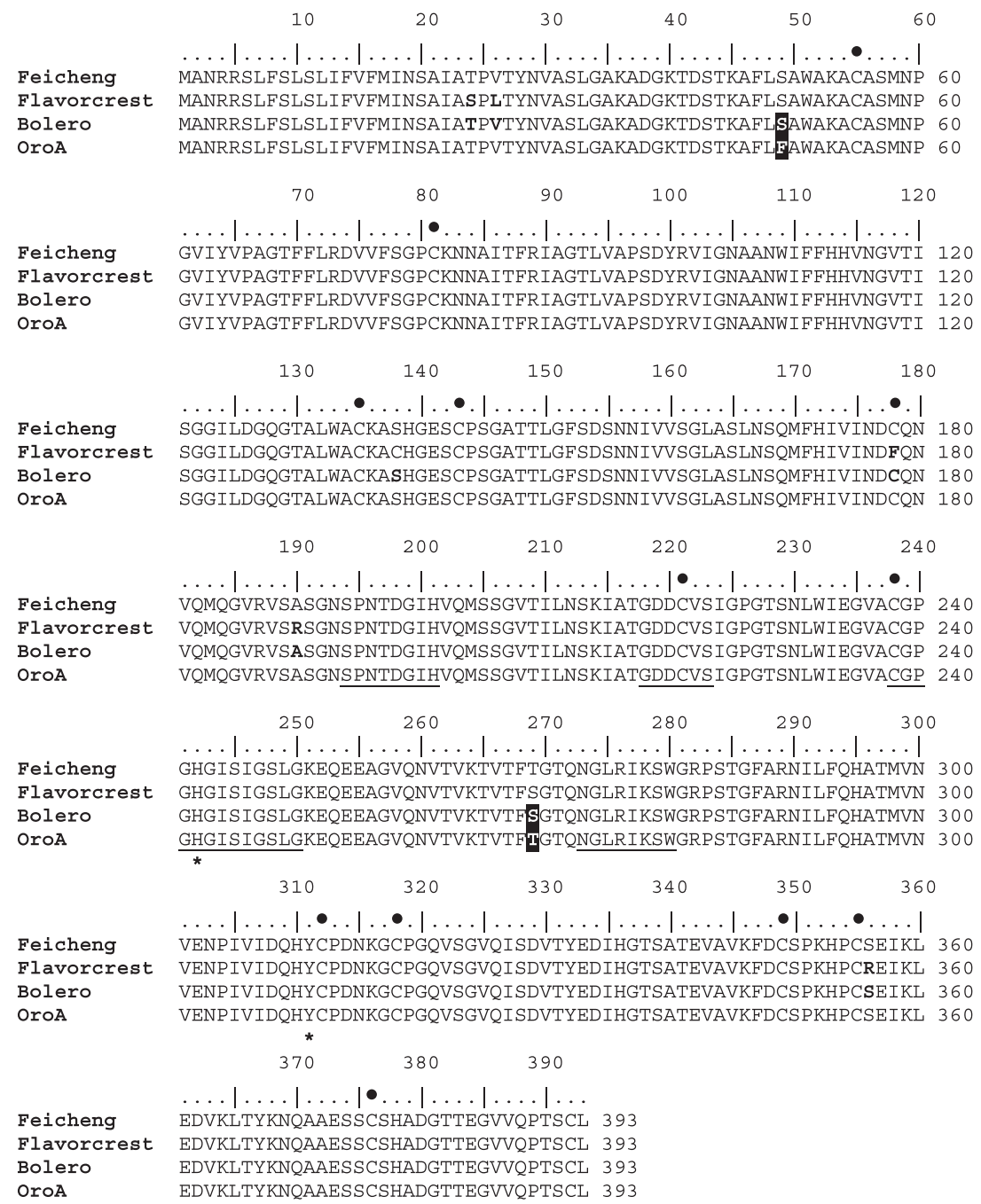

Fig. 3 Amino acid sequence comparison of the predicted peach (Prunus persica) endopolygalacturonase (endo-PG) proteins, as deduced from the cDNA sequences of nonmelting flesh (NMF) 'Feicheng', melting flesh (MF) 'Flavorcrest', MF 'Bolero' and NMF 'Oro A' fruits reported in Fig. 2. Conserved domains with other fruit polygalacturonases are underlined. Dots indicate conserved cysteine residues. Asterisks mark highly conserved $\mathrm{His}$ and Tyr residues essential for activity (Redondo-Nevado et al., 2001). Bold letters indicate differences in amino acids between 'Flavorcrest' (accession no. CAA54150) and 'Bolero'; the reverse contrast indicates differences in amino acids between 'Bolero' and 'Oro A'.

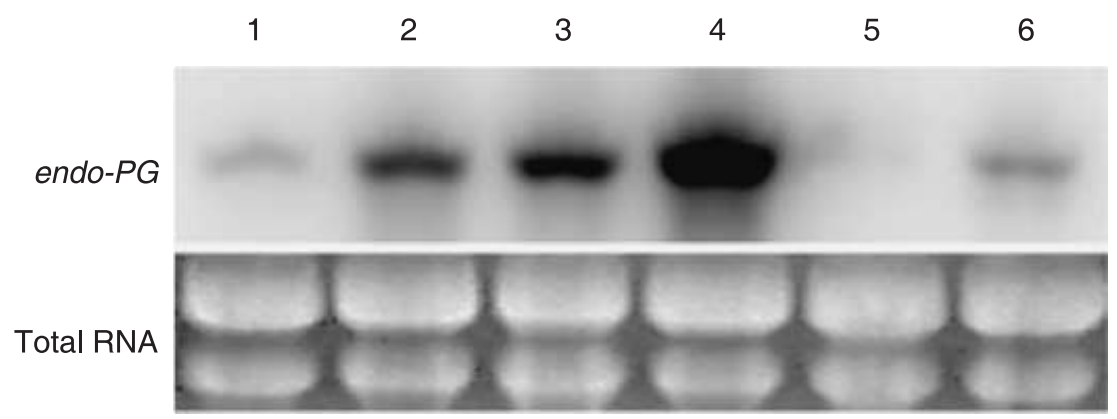

Fig. 4 Expression analysis of an endopolygalacturonase (endo-PG) gene in nonmelting flesh (NMF) 'Oro A' and melting flesh (MF) 'Bolero' peach (Prunus persica) fruits with decreasing flesh firmness. Upper panel: hybridization with the endo- $P G$ cDNA clone from soft MF 'Bolero' fruits. Lane 1, MF 'Bolero' at $54 \mathrm{~N}$; lane 2, MF 'Bolero' at $47 \mathrm{~N}$; lane 3, MF 'Bolero' at $28 \mathrm{~N}$; lane 4, MF 'Bolero' at 12 N; lane 5, NMF 'Oro A' at $46 \mathrm{~N}$; and lane 6, NMF 'Oro A' at $34 \mathrm{~N}$. The lower panel (total RNA) shows the quantification image of the ethidium bromide-stained RNA gel. Twenty micrograms of RNA was loaded per lane; the results of one experiment, representative of three, are shown.

interest, genomic fragments (nucleotide residues 869-2043 relative to the $A C 1$ sequence; see the Materials and Methods) comprising the $\mathrm{SNP} \mathrm{G}_{\mathrm{Bol}} \rightarrow \underline{\mathrm{C}}_{\text {Oro }}$ found at position 806 of the cDNA clones, as well as two intronic sequences. Genomic
DNA was then extracted from the leaves of NMF 'Oro A' and MF 'Bolero', and the selected fragment was subsequently amplified, cloned and sequenced. The results (Fig. 5) showed that all of the 'Oro A' clones yielded a single amplification 
New

Phytologist

869

1172

2043

(a)

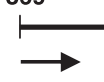

(b)

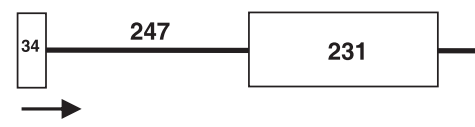

554

106

(c)

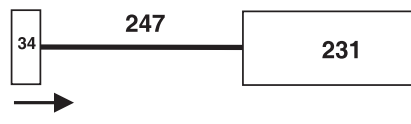

106

(d)

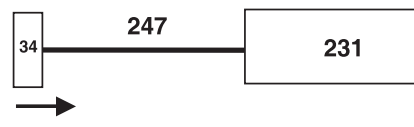

520

106

(e)

$100 \mathrm{bp}$

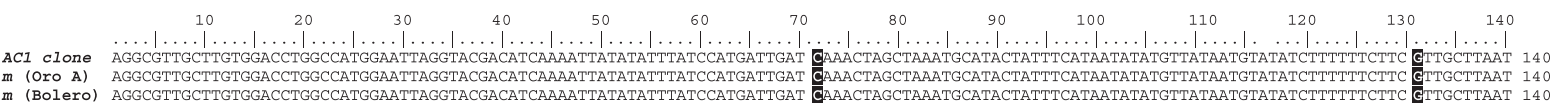

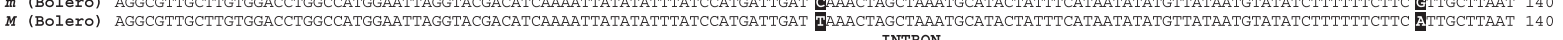

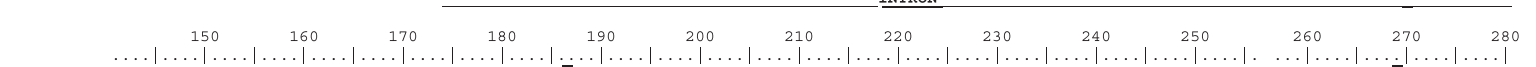

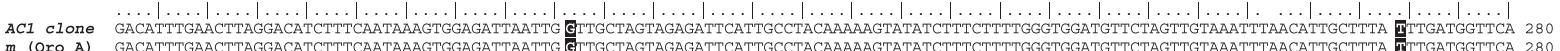

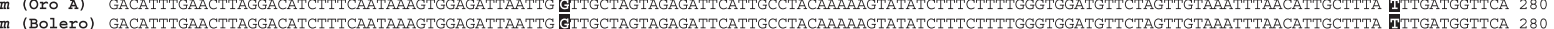

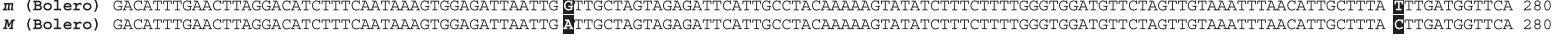

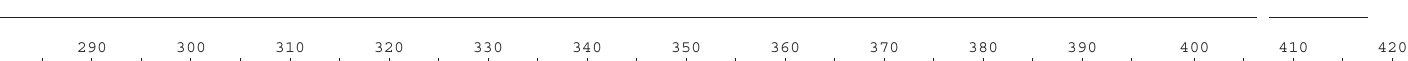

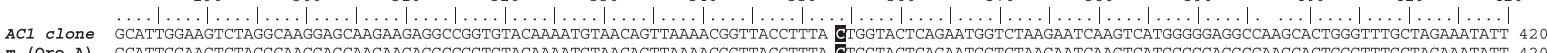

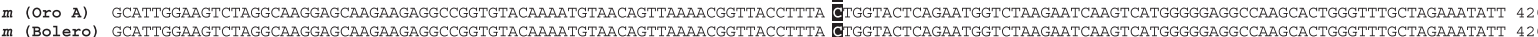
$m$ m (Bolero)
M (Bolero)

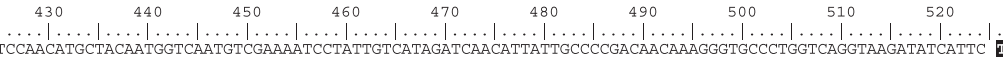
AC1 clone CTTTTCCAACATGCTACAATGGTAATGTCGAAATCCTATTGTCATAGATCAACATTATTGCCCCGACAACAAAGGGTGCCCTGGTCAGGTAAGATATCATTC
$\mathrm{m}(0 \mathrm{O} 0 \mathrm{~A})$ CTTTTCCAACATGCTACAATGGTAATGTCGAAATCCTATTGTCATAGATCAACATTATTGCCCCGACAACAAAGGGTGCCTGGTCAGGTAAGATATCATTC $m$ (Bolero) CTTTTCCAACATGCTACAATGGTCAATGTCGAAAATCCTATTGTCATAGATCAACATTATTGCCCCGACAACAAAGGGTGCCCTGGTCAGGTAAGATATCATT M

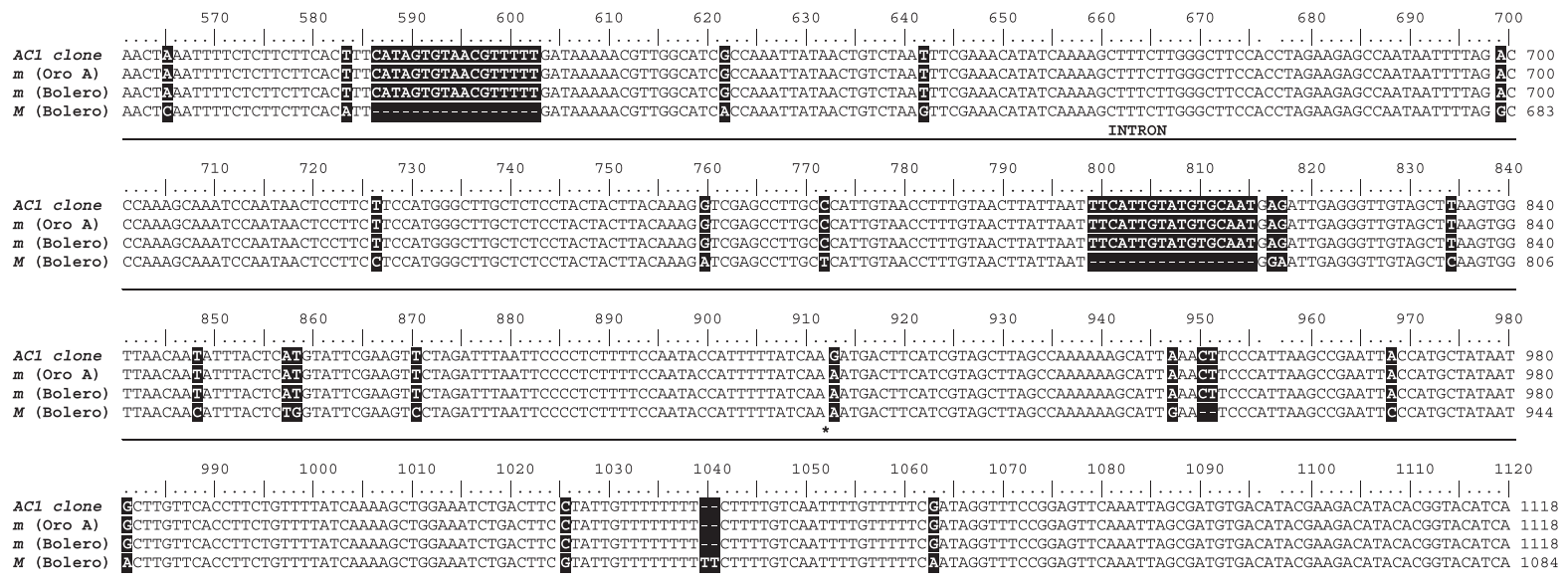

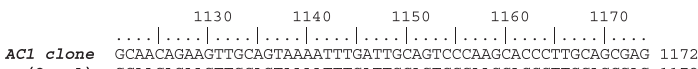

$m$ (Oro A) GCAACAGAAGTTGCAGTAAAATTTGATTGCAGTCCCAAGCACCCTTGCAGCGAG 1172

$m$ (Bolero) GCAACAGAAGTTGCAGTAAAATTTGATTGCAGTCCCAAGCACCCTTGCAGCGAG 1172

Fig. 5 Structure of selected fragments of an endopolygalacturonase (endo-PG) gene in peach (Prunus persica). (a) Position (bp) of the selected fragment within the peach AC1 endo-PG clone (accession no. AY262754). (b) Genomic structure of the AC1 clone. (c) Genomic structure of the $m$ clone. (d) Genomic structure of the $M$ clone. (e) Nucleotide sequence alignment of portions (nucleotide residues 869-2043) of the endo-PG AC1, the $m$ [nonmelting flesh (NMF) 'Oro A' and melting flesh (MF) 'Bolero'], and the $M$ (MF 'Bolero') clones containing the major sequence differences. In (b), (c) and (d), open bars and lines indicate exons and introns, respectively. Numbers indicate lengths (bp) of each sequence. Arrows indicates the direction of the gene. In (e), sequence alignment was performed using the BIOEDIT program. Reverse contrast marks the presence of single nucleotide polymorphisms (SNPs), deletions and insertions; asterisks mark SNPs between AC1 and $m$. The selected DNA fragments were obtained from genomic DNA from NMF 'Oro A' and MF 'Bolero' accessions after amplification with the appropriate primers (see the Materials and Methods). 
product $(m)$ of the predicted length of $1172 \mathrm{bp}$. However, two amplification products were recovered from the 'Bolero' clones, one of which was identical to that of 'Oro A' $(m)$, whereas the other $(M)$ showed a few differences, involving almost exclusively the intronic sequences. In particular, the $M$ fragment showed 31 SNPs, two main deletions of $17 \mathrm{bp}$ each (positions 586-602 and 798-814), a 2-bp deletion (positions 949-950) and a 2-bp insertion (positions 1039-1040). The $M$ fragment was thus shorter by 34 bp than the $m$ fragment (Fig. 5).

The BsrSI-recognizable SNP G $\mathrm{B}_{\mathrm{Bo}} \rightarrow \underline{\mathrm{C}}_{\mathrm{Oro}}$ at position 806 of the cDNA clones (Fig. 2) was found at position 353 of the selected genomic endo- $P G$ sequence in the $m$ allelic configuration typical of 'Oro A' which was also present in the 'Bolero' genotype. Forty-eight base pairs downstream, the second BsrSI-specific restriction site, found in both the $m$ and $M$ allelic configurations, was present (Fig. 5). CAPS analysis was performed on genomic DNA extracted from leaves of the two parents (NMF 'Oro A' and MF 'Bolero') and of the two offspring, NMF 'BO 96014125' and MF 'BO 96014137'. Figure 6 shows that the undigested DNA fragment from both of the NMF accessions considered ('Oro A' and 'BO 96014125') produced a single band (Fig. 6, lanes 2 and 4), with estimated length (approx. $1200 \mathrm{bp}$ ) consistent with that (1172 bp) expected from in silico analysis. Restriction with BsrSI produced two bands with estimated sizes of approx. 770- and 350 bp, respectively (Fig. 6, lanes 3 and 5). In both of the MF accessions 'Bolero' and 'BO 96014137', the undigested DNA fragment produced two bands with only slightly different estimated lengths (Fig. 6, lanes 6 and 8), while restriction with BsrSI produced four bands, of estimated lengths 770-, 730-, 400- and 350 bp (Fig. 6, lanes 7 and 9), confirming a different allelic configuration of the relevant endo-PG gene in NMF and MF accessions.

The same CAPS analysis was repeated on six additional peach genotypes with either NMF ('Andross', 'Jonia', 'BO 82010054') or MF ('Springcrest', 'Springbelle', 'Maycrest') fruit phenotypes. Figure 7 shows that the restriction patterns of the selected endo- $P G$ gene sequence which characterized the NMF and MF accessions described in Fig. 6 were maintained.

\section{Discussion}

The MF trait in peach fruit has been known for many years, the first literature report being by Bailey \& French (1949). Since then, many studies have been conducted to elucidate its biochemical and molecular basis. NMF peaches are reported to contain only exo-PG activity, while MF peaches contain both exo- and endo-PG activities. Moreover, ripe MF fruits present much higher endo-PG activity than NMF fruits (Pressey \& Avants, 1973, 1978). These biochemical findings were supported by results obtained from northern analysis showing that in the NMF peach 'Carolyn' transcription of the endo-PG gene occurred as well as in MF phenotypes, but with an RNA transcript of approx. $250 \mathrm{bp}$ shorter, combined with failure in production of the endo-PG protein, as shown by immunoblotting (Lester et al., 1994, 1996). In another NMF cultivar, 'Fla.9-20C', Southern analysis showed complete absence of endo-PG-related bands, suggesting deletion of a portion of the gene (Lester et al., 1996). Consistent results were also obtained for eight other NMF cultivars, where greatly reduced or undetectable levels of endo-PG PRF5-related PG mRNA were found (Callahan et al., 2004). These data were interpreted as probably reflecting the presence of a sequence

bp

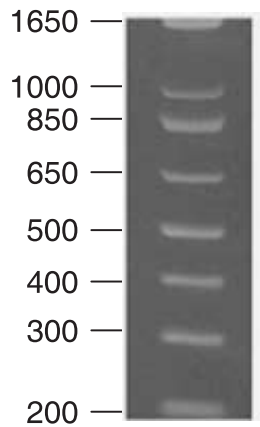

1

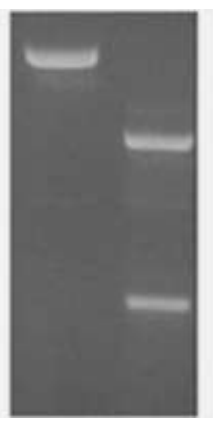

23

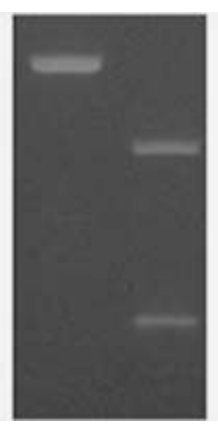

45

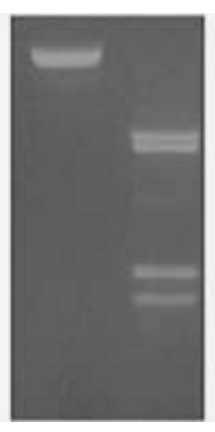

$6 \quad 7$

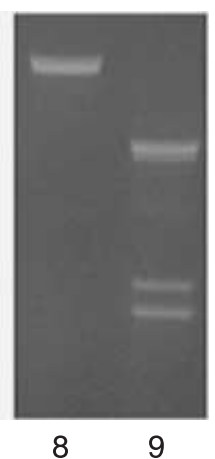

Fig. 6 Cleaved amplified polymorphic sequence (CAPS) restriction patterns of genomic DNA from leaves of peach (Prunus persica) accessions with nonmelting flesh (NMF) ('Oro A', 'BO 96014125') or melting flesh (MF) ('Bolero', 'BO 96014137') fruit phenotypes. Selected genomic DNA fragments of the $A C 1$ endopolygalacturonase (endo- $P G$ ) clone, obtained as described in the Materials and Methods, were restricted with $B s r S I$. Lane 1, 1-kb DNA ladder; lane 2, undigested endo- $P G$ gene sequence from 'Oro A'; lane 3, BsrSI-digested endo- $P G$ gene fragments from 'Oro A'; lane 4, same as lane 2, from 'BO 96014125'; lane 5, BsrSI-digested endo-PG gene fragments from 'BO 96014125'; lane 6, same as lane 2, from 'Bolero'; lane 7, BsrSI-digested endo-PG gene fragments from 'Bolero'; lane 8, same as lane 2, from 'BO 96014137'; and lane 9, $B s r S I-d i g e s t e d$ endo- $P G$ gene fragments from 'BO 96014137'. Twenty micrograms of DNA was loaded per lane; the results of one experiment, representative of three, are shown. 
New

Phytologist

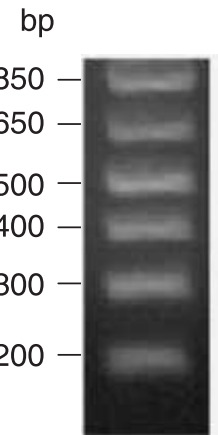

1

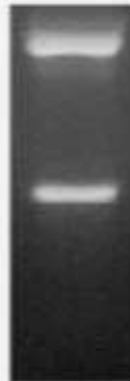

2

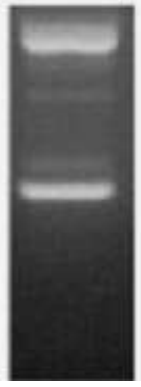

3

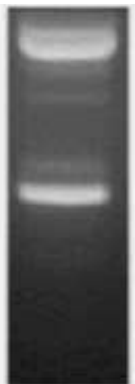

4

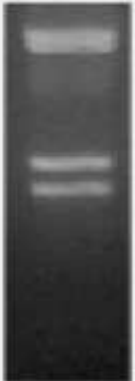

5

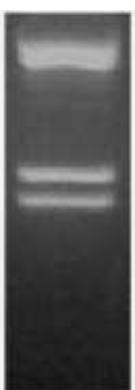

6

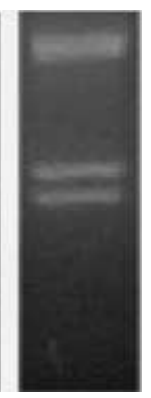

7

Fig. 7 Cleaved amplified polymorphic sequence (CAPS) restriction patterns of genomic DNA from leaves of peach (Prunus persica) accessions with nonmelting flesh (NMF) ('Andross', 'Jonia' and 'BO 82010054') or melting flesh (MF) ('Springcrest', 'Springbelle' and 'Maycrest') fruits. Selected genomic DNA fragments of the AC1 endopolygalacturonase (endo-PG) clone, obtained as described in the Materials and Methods, were restricted with BsrSI. Lane 1, 1-kb DNA ladder; lane 2, BsrSI-digested endo-PG gene fragments from 'Andross'; lane 3, same as lane 2, from 'Jonia'; lane 4, same as lane 2, from 'BO 82010054'; lane 5, same as lane 2, from 'Springcrest'; lane 6, same as lane 2, from 'Springbelle'; and lane 7, same as lane 2, from 'Maycrest'. Twenty micrograms of DNA was loaded per lane; the results of one experiment, representative of three, are shown.

aberration affecting translation and/or production of an active form of the enzyme in NMF peaches.

The work described here shows that an endo-PG gene, corresponding to that expressed in ripe peach fruits (acc. no. $\mathrm{X} 76735$ ) was present and expressed, albeit at different extents, in both groups of NMF and MF fruits assessed (Figs 2, 4). Moreover, the same polyclonal antibodies raised against a conserved sequence of an endo-PG form of ripe peaches recognized, among the proteins extracted from the cell walls of ripe MF 'Bolero' fruits, a protein with endo-PG activity (Fig. 1a,b), and in both NMF and MF fruits, a polypeptide (Fig. 1c), whose molecular mass (approx. $45 \mathrm{kDa}$ ) closely matched that reported for mature endo-PGs (Lee et al., 1990 and references therein; Brummell \& Harpster, 2001). These findings give sound circumstantial evidence that a corresponding endo-PG polypeptide was produced and delivered into the mesocarp cell walls (Fig. 1c).

The lower proportion, in NMF as compared with MF fruits, of ripe-fruit endo-PG polypeptide (in relation to the total proteins extractable in saline conditions from the cell walls; Fig. 1c) was consistent with the different levels of ripe-fruit endo- $P G \mathrm{mRNA}$ observed in the NMF and MF fruits assessed (lower in NMF 'Oro A', higher and increasing with softening in MF 'Bolero') (Fig. 4), suggesting a regulation of endo-PG production at the transcriptional level, in relation to both phenotype and degree of softening. Nevertheless, some other type of regulation at translational or post-translational levels cannot be excluded, as suggested for the production of the active form of tomato fruit PG (DellaPenna \& Bennett, 1988).

In vitro specific endo-PG activities (expressed on a perprotein basis) were generally higher (by approx. $100 \%$ ) in MF than in NMF fruits, consistent with the lower degree of flesh softening of NMF fruits as compared with MF fruits. Nevertheless, the presence of other endo-PG isoforms, not specifically involved in the process of ripening-related flesh softening, cannot be excluded, as suggested by the measurable amounts of in vitro endo-PG activity found also in 'Oro A' and 'BO 96014125' NMF fruits, where the levels of the endo-PG polypeptide typical of ripe, soft fruits were extremely low (Fig. 1c, lanes 1-5). A higher proportion, in MF fruits, of the endo-PG isoform, specifically involved in ripening-related fruit softening and recognized by the antibodies used, may also explain the higher levels of endo-PG polypeptide observed in firmer $(54 \mathrm{~N}) \mathrm{MF}$ 'Bolero' fruits as compared with softer ( $46 \mathrm{~N}) \mathrm{NMF}$ 'Oro A' fruits (Fig. 1c, lanes 6 and 1, respectively). Early synthesis and secretion into the cell wall of the endo-PG protein seems thus to precede, in MF fruits, the actual flesh softening, in agreement with the general understanding that this complex phenomenon is a result of the ordered and sequential expression of many genes involved in the modification of the cell wall structure (Trainotti et al., 2003).

The NMF 'Oro A' did not show any large differences at the level of the endo- $P G$ transcript considered, as shown by the identical lengths (1182 bp) of the endo- $P G$ cDNA clones obtained from either 'Oro A' or 'Bolero' fruits. Nevertheless, the 'Oro A' endo-PG cDNA clone showed five SNPs compared with that of 'Bolero' (Fig. 2). Three (nucleotide positions 516,576 , and 579) did not induce any change in the deduced amino acid sequence (Fig. 3), whereas the SNP at position 806 bp induced the substitution of a Ser residue (MF 'Bolero') with Thr (NMF 'Oro A') at position 269 of the deduced amino acid sequence of the protein. This change is conservative in terms of amino acid properties. However, the SNP at nucleotide position 146 induced a change in position 49 of the amino acid sequence, from Ser ('Bolero') to Phe ('Oro A'). It cannot be excluded that this change may alter the properties of the endo-PG protein.

Further investigation, at the molecular level (sequencing and CAPS analysis), of the selected endo- $P G$ gene fragments 
from NMF and MF accessions, gave interesting information. The genomic DNA fragments obtained from 'Oro A' and 'Bolero' by amplification of the selected endo- $P G$ gene sequence comprising the nucleotide residue mutated in 'Oro A' $\left(\mathrm{C}_{\text {Oro }}\right)$ as compared with 'Bolero' $\left(\mathrm{G}_{\mathrm{Bol}}\right)$, were of one type only $(m)$ in 'Oro A', whereas in 'Bolero' there were two different types of fragments ( $m$ and $M$; Fig. 5), indicating homozygosis $(\mathrm{m} / \mathrm{m})$ at the $M$ locus for 'Oro A' and heterozygosis $(\mathrm{m} / \mathrm{M})$ for 'Bolero'. The heterozygous nature at the $M$ locus of 'Bolero' was then confirmed in a progeny raised by self-pollination (D. Bassi, unpublished). The $m$ fragment (present in both 'Oro A' and 'Bolero'), with the BsrSI-restrictable SNP at position $353 \mathrm{bp}$, presented two restriction sites, expected to produce three fragments of, respectively, 767-, 357-, and $48 \mathrm{bp}$. The $M$ fragment (only one BsrSI restriction site), present in one copy in 'Bolero', was expected to produce two fragments, of 733- and $405 \mathrm{bp}$, respectively, because of the shorter (by $34 \mathrm{bp}$ ) length of the original DNA sequence. For the sake of clarity, the schemes depicted in Fig. 8 illustrate the expected lengths of the restriction fragments (Fig. 8a) as well as the expected gel-separation patterns (Fig. 8b) for homozygous $(\mathrm{m} / \mathrm{m} ; M / M)$ or heterozygous $(\mathrm{m} / \mathrm{M})$ allelic configurations, respectively. In both 'Oro A' and 'BO 96014125' only two bands (corresponding to DNA fragments of approx. 770- and $350 \mathrm{bp}$, respectively) could be observed, confirming the presence of two identical $m$ alleles $(\mathrm{m} / \mathrm{m})$ in the NMF accessions. In the MF accessions 'Bolero' and 'BO 96014137', four bands were detected after digestion with BsrSI: two bands (approx. 770 - and $350 \mathrm{bp}$ ) apparently originated from the $m$ allele, and two (approx. 730- and $400 \mathrm{bp)}$ ) originated from the $M$ allele (Fig. 6). Considering that a 48-bp DNA fragment is surely too small to be retained in the $2 \%$ agarose gel used, the results are in good agreement with those expected from Fig. 8, and are consistent with data recently obtained in peach accessions derived from 'Dr Davis' or/and 'Georgia Belle' cultivars, showing that DNA sequence differences for different endo$P G$ alleles in NMF/MF phenotypes are in the form of SNPs and indels involving an intronic sequence. In particular, the $\mathrm{F}^{\mathrm{b}}$ intronic sequence of the endo- $P G$ gene, which is hypothesized to characterize the MF phenotype in 'Dr Davis' $\times$ 'Georgia Belle' progeny, shows the same loss of two 17-bp sequences (Peace et al., 2005) as that reported in the present work for the $M$ allele in the MF germplasm (Figs 6 and 7). This result may suggest a possible regulatory role of the considered intronic sequence (Lorković et al., 2000) for the expression of the endo- $P G$ gene during fruit ripening.

Also interesting is the finding that the SNP observed in the NMF 'Oro A' endo-PG ORF at 806 bp (Fig. 2) is also conserved in another NMF cultivar, the chinese 'Feicheng' (Ma et al., 1999, acc. no. AF095577). On the basis of the results reported in the literature about different NMF peach germplasm, it appears very likely that mutations in the endo-PG gene, causing absence of expression of the endo-PG protein, could be of more than one type, and that the NMF (a)

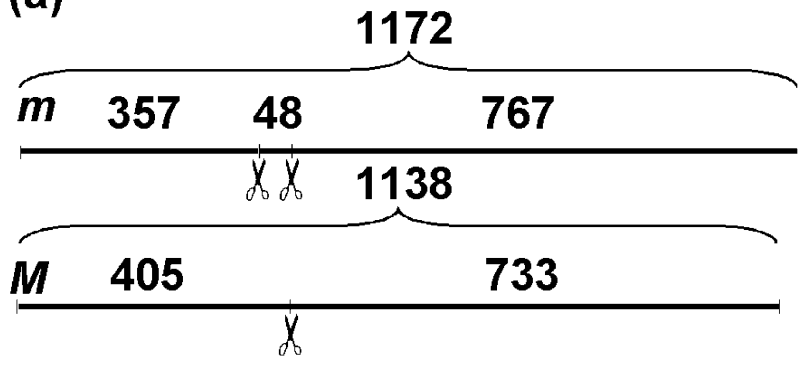

(b)

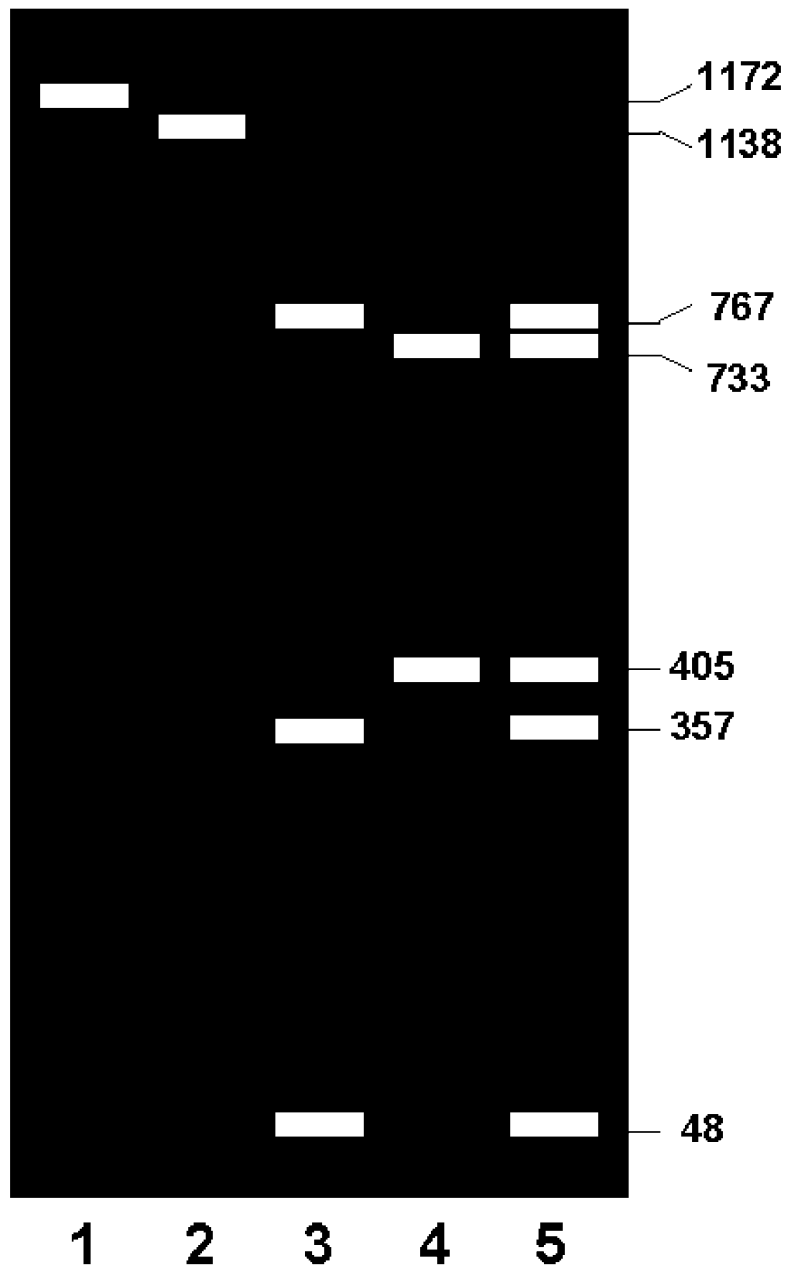

Fig. 8 Restriction fragments expected from the digestion, by BsrSI, of a selected sequence [1172 bp; nucleotides 869-2043 of the AC1 endopolygalacturonase (endo-PG) clone from peach (Prunus persica)] of the peach endo- $P G$ genomic sequences of $m$ and $M$ clones. (a) Numbers above the curly brackets indicate total length (bp) of the selected $m$ and $M$ endo- $P G$ gene fragments, respectively. Numbers above the lines indicate the expected lengths (bp) of the restriction fragments obtained after digestion with $B s r S I$ of the $m$ and $M$ endo- $P G$ clone fragments. (b) Expected gel-separation patterns of the DNA fragments shown in (a). Lane 1, undigested $m$ endo-PG clone fragment; lane 2, undigested $M$ endo- $P G$ clone fragment; lane 3, BsrSI-digestion pattern for the $\mathrm{m} / \mathrm{m}$ allelic configuration; lane 4, BsrSI-digestion pattern for the $M / M$ allelic configuration; and lane 5, $B s r S I-d i g e s t i o n$ pattern for the $m / M$ allelic configuration. 
trait has arisen from more than one source differently distributed in the different growing areas (Lester et al., 1996; Callahan et al., 2004). However, the results concerning the NMF/MF peach accessions studied in the present work (Figs 6, 7) seem to indicate that the same polymorphism in the same position of the $m$ allele of the endo-PG gene is conserved among different accessions with NMF phenotype.

This seems to represent satisfactory preliminary evidence for the possible use of this SNP to develop a molecular marker useful for predicting the fruit phenotype in newly established peach accessions. The same SNP may also be exploited for identifying the genetic asset at the melting flesh $(M)$ locus in a progeny homozygous and heterozygous for this locus.

\section{Acknowledgements}

The research was funded by the Centre for Bio-Molecular Interdisciplinary Studies and Industrial Applications (CISI), University of Milan and by the Italian MIUR PRIN-COFIN Project 'Fruit ripening and quality: molecular and biochemical aspects of softening and of the development of components with high alimentary and nutraceutic value'.

\section{References}

Abbott AG, Rajapakse S, Sosinski B, Lu ZX, Sossey-Alaoui K, Gannavarapu M, Reighard G, Ballard RE, Baird WV, Scorza R, Callahan A. 1998. Construction of saturated linkage maps of peach crosses segregating for characters controlling fruit quality, tree architecture and pest resistance. Acta Horticulturae 465: 41-49.

Bailey JS, French AP. 1949. The Inheritance of Certain Fruit and Foliage Characters in the Peach. Massachusetts Agricultural Experimental Station Bulletin 452. Amherst, MA, USA: University of Massachusetts, 2-31.

Bonghi C, Ferrarese L, Ruperti B, Tonutti P, Ramina A. 1998. Endo- $\beta-1,4-$ glucanases are involved in peach fruit growth and ripening, and regulated by ethylene. Physiologia Plantarum 102: 346-352.

Bradford MM. 1976. A rapid and sensitive method for the quantitation of microgram quantities of protein utilizing the principle of protein-dye binding. Analytical Biochemistry 72: 248-254.

Brovelli EA, Brecht JK, Sherman WB, Sims CA. 1998. Potential maturity indices and developmental aspects of melting- and non melting flesh peach genotypes for the fresh market. Journal of the American Society for Horticultural Science 123: 438-444.

Bruhn CM. 1994. Consumer and retailer satisfaction with the quality and size of California peaches and nectarines. Journal of Food Quality 18: 241256.

Brummell DA, Harpster MH. 2001. Cell wall metabolism in fruit softening and quality and its manipulation in transgenic plants. Plant Molecular Biology 47: 311-340.

Brummell DA, Dal Cin V, Crisosto CH, Labavitch JM. 2004. Cell wall metabolism during maturation, ripening and senescence of peach fruit. Journal of Experimental Botany 55: 2029-2039.

Callahan AM, Scorza R, Bassett C, Nickerson M, Abeles FB. 2004. Deletions in an endopolygalacturonase gene cluster correlate with non-melting flesh texture in peach. Functional Plant Biology 31 : 159-168.

DellaPenna D, Bennett AB. 1988. In vitro synthesis and processing of tomato fruit polygalacturonase. Plant Physiology 86: 1057-1063.

Delwiche MJ, Baumgardner RA. 1985. Ground color as a peach maturity index. Journal of the American Society for Horticultural Science 110: 53-57.
Dirlewanger E, Pronier V, Parvery C, Rothan C, Guye A, Monet R. 1998. Genetic linkage map of peach [Prunus persica (L.) Batsch] using morphological and molecular markers. Theoretical and Applied Genetics 97: $888-895$.

Dirlewanger E, Moing A, Rothan C, Svanella L, Pronier V, Guye A, Plomion C, Monet R. 1999. Mapping QTLs controlling fruit quality in peach [Prunus persica (L.) Batsch]. Theoretical and Applied Genetics 98: $18-31$.

Etienne C, Rothan C, Moing A, Plomion C, Bodénès C, Svanella-Dumas L, Cosson P, Pronier V, Monet R, Dirlewanger E. 2002. Candidate genes and QTLs for sugar and organic content in peach [Prunus persica $(\mathrm{L}$. Batsch]. Theoretical and Applied Genetics 105: 145-159.

Fischer RL, Bennett AB. 1991. Role of cell wall hydrolases in fruit ripening. Annual Review of Plant Physiology and Plant Molecular Biology 42: 675703.

Geuna F, Maitti C, Digiuni S, Banfi R. 2004. A method for the extraction of genomic DNA from plant tissues rich in contaminating compounds suitable for medium-throughput applications. Plant Molecular Biology Reporter 22: 1-5.

Gross KC. 1982. A rapid and sensitive method for assaying polygalacturonase using 2-cyanoacetamide. Hortscience 17: 933-934.

Hadfield KA, Bennett AB. 1998. Polygalacturonases: many genes in search of a function. Plant Physiology 117: 337-343.

Hadfield KA, Rose JKC, Yaver DS, Berka RM, Bennett AB. 1998. Polygalacturonase gene expression in ripe melon fruit supports a role for polygalacturonase in ripening-associated pectin disassembly. Plant Physiology 117: 363-373.

Hatfield R, Nevins D. 1986. Characterization of the hydrolytic activity of avocado cellulase. Plant and Cell Physiology 27: 541-552.

Heukeshoven J, Dernick R. 1985. Simplified method for silver staining of proteins in polyacrylamide gels and the mechanism of silver staining. Electrophoresis 6: 103-112.

Hiwasa K, Kinugasa Y, Amano S, Hashimoto A, Nakano R, Inaba A, Kubo Y. 2003. Ethylene is required for both the initiation and progression of softening in pear (Pyrus communis L.) fruit. Journal of Experimental Botany 54: 771-779.

Huh JH, Kang BC, Nahm SH, Kim S, Ha KS, Lee MH, Kim BD. 2001. A candidate gene approach identified phytoene synthase as the locus for mature fruit color in red pepper (Capsicum spp.). Theoretical and Applied Genetics 102: 524-530.

Klann EM, Hall B, Bennett AB. 1996. Antisense acid invertase (TIV1) gene alters soluble sugar composition and size in transgenic tomato fruit. Plant Physiology 112: 1321-1330.

Koniekzny A, Ausubel FM. 1993. A procedure for mapping Arabidopsis mutations using co-dominant ecotype-specific PCR-based markers. Plant Journal 4: 403-410.

Laemmli UK. 1970. Cleavage of structural proteins during the assembly of the head of bacteriophage T4. Nature 227: 680-685.

Lee E, Speirs J, Brady CJ. 1990. Homologies to the tomato endopolygalacturonase gene in the peach genome. Plant, Cell \& Environment 13: 513-521.

Lester DR, Speirs G, Orr G, Brady CJ. 1994. Peach (Prunus persica) endo$P G$ cDNA isolation and mRNA analysis in melting and non-melting peach cultivars. Plant Physiology 105: 225-231.

Lester DR, Sherman WB, Atwell BJ. 1996. Endopolygalacturonase and the Melting flesh (M) locus in peach. Journal of the American Society for Horticultural Science 121: 231-235.

Lorković ZJ, Wieczorek Kirk DA, Lambermon MHL, Filipowicz W. 2000. Pre-mRNA splicing in higher plants. Trends in Plant Science 5: 160-167.

Loulakakis KA, Roubelakis-Angelakis KA, Kanellis AK. 1996. Isolation of functional RNA from grapevine tissues poor in nucleic acid content. American Journal of Enology and Viticulture 47: 181-185.

Ma QH, Wang LM, Song YR, Zhu ZQ. 1999. Cloning and expression of a cDNA encoding polygalacturonase from Feicheng peach (Prunus persica). Acta Botanica Sinensia 41: 263-267. 
Moore T, Bennett AB. 1994. Tomato fruit polygalacturonase isozyme 1. Characterization of the $\beta$ subunit and its state of assembly in vivo. Plant Physiology 106: 1461-1469.

Orr G, Brady C. 1993. Relationship of endopolygalacturonase activity to fruit softening in a freestone peach. Postharvest Biology and Technology 3: 121-130.

Peace CP, Crisosto CH, Gradziel TM. 2005. Endopolygalacturonase: a candidate gene for Freestone and Melting flesh in peach. Molecular Breeding 16: 21-31.

Pressey R, Avants JK. 1973. Separation and characterization of endopolygalacturonase and exopolygalacturonase from peaches. Plant Physiology 52: 252-256.

Pressey R, Avants JK. 1978. Differences in polygalacturonase composition of clingstone and freestone peaches. Journal of Food Science 43: 1415-1423.

Quarta R, Dettori MT, Sartori A, Verde I. 2000. Genetic linkage map and QTL analysis in peach. Acta Horticulturae 521: 233-241.

Rao GU, Paran I. 2003. Polygalacturonase: a candidate gene for the soft flesh and deciduous fruit mutation in Capsicum. Plant Molecular Biology 51: $135-141$.
Redondo-Nevado J, Moyano E, Medina-Escobar N, Caballero JL, Munoz-Blanco J. 2001. A fruit-specific and developmentally regulated endopolygalacturonase gene from strawberry (Fragaria $\times$ ananassa cv. Chandler). Journal of Experimental Botany 52: 1941-1945.

Robertson JA, Horvat RJ, Lyon BG, Meredith FI, Senter S, Okie WR. 1990. Comparison of quality characteristics of selected yellow- and white-fleshed peach cultivars. Journal of Food Science 55: 1308-1311.

Schägger H, von Jagow G. 1987. Tricine-sodium dodecyl sulfatepolyacrylamide gel electrophoresis for the separation of proteins in the range from 1 to $100 \mathrm{kDa}$. Analytical Biochemistry 166: 368-379.

Trainotti L, Zanin D, Casadoro G. 2003. A cell wall-oriented genomic approach reveals a new and unexpected complexity of the softening in peaches. Journal of Experimental Botany 54: 1821-1832.

Westwood M. 1978. Fruit growth and thinning. In: Westwood MN, ed. Temperate-zone pomology. San Francisco, CA, USA: W.H. Freeman, 199-201.

Yen H, Lee S, Tanksley SD, Lanahan MB, Klee HJ, Giovannoni JJ. 1995. The tomato never-ripe locus regulates ethylene-inducible gene expression and is linked to a homolog of the Arabidopsis ETR 1 gene. Plant Physiology 107: $1343-1353$.

\section{About New Phytologist}

- New Phytologist is owned by a non-profit-making charitable trust dedicated to the promotion of plant science, facilitating projects from symposia to open access for our Tansley reviews. Complete information is available at www.newphytologist.org.

- Regular papers, Letters, Research reviews, Rapid reports and both Modelling/Theory and Methods papers are encouraged. We are committed to rapid processing, from online submission through to publication 'as-ready' via OnlineEarly - the 2004 average submission to decision time was just 30 days. Online-only colour is free, and essential print colour costs will be met if necessary. We also provide 25 offprints as well as a PDF for each article.

- For online summaries and ToC alerts, go to the website and click on 'Journal online'. You can take out a personal subscription to the journal for a fraction of the institutional price. Rates start at $£ 109$ in Europe/\$202 in the USA \& Canada for the online edition (click on 'Subscribe' at the website).

- If you have any questions, do get in touch with Central Office (newphytol@lancaster.ac.uk; tel +44 1524 594691) or, for a local contact in North America, the US Office (newphytol@ornl.gov; tel +1 865576 5261). 